\title{
Inhibition of Proinflammatory Enzymes and Attenuation of IL-6 in LPS-Challenged RAW 264.7 Macrophages Substantiates the Ethnomedicinal Use of the Herbal Drug Homalium bhamoense Cubitt \& W.W.Sm
}

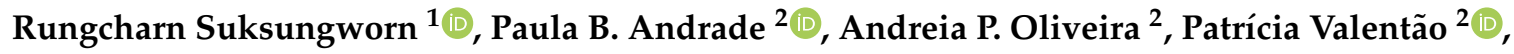 \\ Sutsawat Duangsrisai ${ }^{1, *}$ and Nelson G. M. Gomes ${ }^{2, *(D)}$ \\ 1 Department of Botany, Faculty of Science, Kasetsart University, Ngam Wong Wang Road, Chatuchak, \\ Bangkok 10900, Thailand; b5310402969@gmail.com \\ 2 REQUIMTE/LAQV, Laboratório de Farmacognosia, Departamento de Química, Faculdade de Farmácia, \\ Universidade do Porto, R. Jorge Viterbo Ferreira, nº 228, 4050-313 Porto, Portugal; \\ pandrade@ff.up.pt (P.B.A.); asoliveira@ff.up.pt (A.P.O.); valentao@ff.up.pt (P.V.) \\ * Correspondence: fscissw@ku.ac.th (S.D.); ngomes@ff.up.pt (N.G.M.G.); Tel.: +66-25625555 (S.D.); \\ +351-220428500 (N.G.M.G.)
}

Received: 3 March 2020; Accepted: 31 March 2020; Published: 31 March 2020

\begin{abstract}
Commonly used to treat skin injuries in Asia, several Homalium spp. have been found to promote skin regeneration and wound healing. While ethnobotanical surveys report the use of $H$. bhamoense trunk bark as a wound salve, there are no studies covering bioactive properties. As impaired cutaneous healing is characterized by excessive inflammation, a series of inflammatory mediators involved in wound healing were targeted with a methanol extract obtained from H. bhamoense trunk bark. Results showed concentration-dependent inhibition of hyaluronidase and 5-lipoxygenase upon exposure to the extract, with $\mathrm{IC}_{50}$ values of $396.9 \pm 25.7$ and $29.0 \pm 2.3 \mu \mathrm{g} \mathrm{mL}^{-1}$, respectively. $H$. bhamoense trunk bark extract also exerted anti-inflammatory activity by significantly suppressing the overproduction of interleukin 6 (IL-6) in lipopolysaccharide (LPS)-stimulated RAW 264.7 macrophages at concentrations ranging from 125 to $1000 \mu \mathrm{g} \mathrm{mL}{ }^{-1}$, while leading to a biphasic effect on nitric oxide (NO) and tumor necrosis factor alpha (TNF- $\alpha$ ) levels. The phenolic profile was elucidated by HPLC-DAD, being characterized by the occurrence of ellagic acid as the main constituent, in addition to a series of methylated derivatives, which might underlie the observed anti-inflammatory effects. Our findings provide in vitro data on anti-inflammatory ability of $H$. bhamoense trunk bark, disclosing also potential cutaneous toxicity as assessed in HaCaT keratinocytes.
\end{abstract}

Keywords: cytokines; Homalium tomentosum; hyaluronan; interleukins; methyl ellagic acid; polyphenols; traditional medicine

\section{Introduction}

Currently comprising over 70 accepted species listed on The Plant List database (version 1.1 2020; http://www.theplantlist.org), Homalium is a genus of deciduous medium-sized trees with a predominant distribution in temperate and subtropical regions [1]. Several members of the genus have been reported due to their use in folk medicine, but data on the pharmacological properties are generally scant. So far, available studies on Homalium spp. have demonstrated relevant biological activities frequently related to their ethnomedicinal uses, such as antibacterial [2], antidiabetic [3], antinociceptive [4] and anti-inflammatory [3,4]. 
Ethnobotanical surveys revealed that some Homalium species are used as wound healing remedies; Homalium zeylanicum Benth. is generally referred to as a wound healing plant [1,5]; leaves from Homalium foetidum Benth. are used by tribes from Papua New Guinea to treat topical ulcers and subcutaneous skin infections $[2,6]$. While there are no available studies on the biological properties of Homalium bhamoense Cubbit \& W.W.Sm., surveys indicate its utility against common ailments, such as joint pain and fever [1]. Known in Thailand as "kha nang" [7], the roots of the plant are used as an astringent in the neighbouring countries [8], while the leaves and trunk bark are widely used as wound healing remedies also in eastern India [1].

Wound healing is an utterly complex process involving an array of finely tuned steps, from initial injury to the final reconstituted tissue, with inflammatory mediators orchestrating a series of events throughout most of the process [9]. For example, the metabolic products of hyaluronidase and 5-lipoxygenase (5-LOX) function as microenvironmental cues, actively participating in the regulation of healing processes and inflammation $[10,11]$. Nitric oxide (NO) acts as a mediator of skin homeostasis and wound repair, influencing collagen deposition and the strength of incisional wounds [12]. Also cytokines, including tumor necrosis factor alpha (TNF- $\alpha$ ) and interleukin 6 (IL-6), act as signalling molecules, being closely involved in the very early events of wound healing through the recruitment of inflammatory cells in the dermal and epidermal layers, synthesis of extracellular matrix proteins and regulation of the immune response [13].

A myriad of wound-healing plants have been identified based on ethnobotanical records, a significant number of species used as wound salves in folk medicine exhibiting potent inhibitory effects towards extracellular matrix enzymes. Many species also display ameliorating effects against several additional mediators of inflammation, thus proving to promote the healing rate and reducing scar formation [14]. Worthy of mention is also the increasing number of reports dealing with the development of topical formulations aiming to enhance the anti-inflammatory and skin regeneration properties of herbal extracts [15-17], namely nanometric vesicles containing molecules of hyaluronate (hyalurosomes) [16,17].

Due to the scant data on the biological potential of $H$. bhamoense, and also prompted by its ethnomedicinal use, inhibitory effects of a methanol extract obtained from the trunk bark were assessed with regard to a series of inflammatory mediators. Since a persistent inflammatory response derived from skin tissue injury can lead to elevated levels of proinflammatory enzymes and accumulation of free radicals, potential inhibitory properties towards hyaluronidase and 5-LOX were evaluated, as well as the interference with NO levels, both using RAW 264.7 macrophages stimulated with lipopolysaccharide (LPS) and a cell-free assay. The amount of cytokines (TNF- $\alpha$ and IL-6) released by LPS-challenged RAW 264.7 cells was also measured by ELISA. Additionally, the effects upon the viability of the skin representative cell line $\mathrm{HaCaT}$ were evaluated in order to deliver data on topical safety.

Chemical profiling of the extract obtained from the trunk bark was also attained so that one may provide an HPLC fingerprint, also allowing identification of bioactives that may underlie the observed biological effects.

\section{Results and Discussion}

\subsection{HPLC-DAD Characterization of the Phenolic Profile of H. bhamoense Trunk Bark Extract}

Previous studies on the most extensively investigated species, Homalium ceylanicum (Gardner) Benth. and Homalium stenophyllum Merr. \& Chun, have afforded an array of compounds including phenolic acids [18-20], isocoumarins [20] and flavonoids [20,21]. However, unlike other Homalium species, there are no reports on the chemical profile of $H$. bhamoense. As such, the methanol extract obtained from the trunk bark was investigated in order to deliver an HPLC-based authenticating fingerprint on the plant material, as well as to tentatively identify bioactive polyphenolic constituents. 
Comparison with an internal database [22] and authentic standards allowed the identification and quantitation of ellagic acid (1), methyl ellagic acid (4) and the two glycosylated methyl ellagic acid derivatives $\mathbf{2}$ and $\mathbf{3}$ (Figure 1 and Table 1 ). While the trunk bark extract is predominantly characterized by the presence of methyl ellagic acid derivatives (2-4), ellagic acid (1) was identified as the main phenolic component, representing ca. $43 \%$ of the quantifiable total (Table 1 ). The phenolic profile of the species is here disclosed for the first time, simultaneously delivering data on the occurrence of ellagic acid derivatives in the genus Homalium.

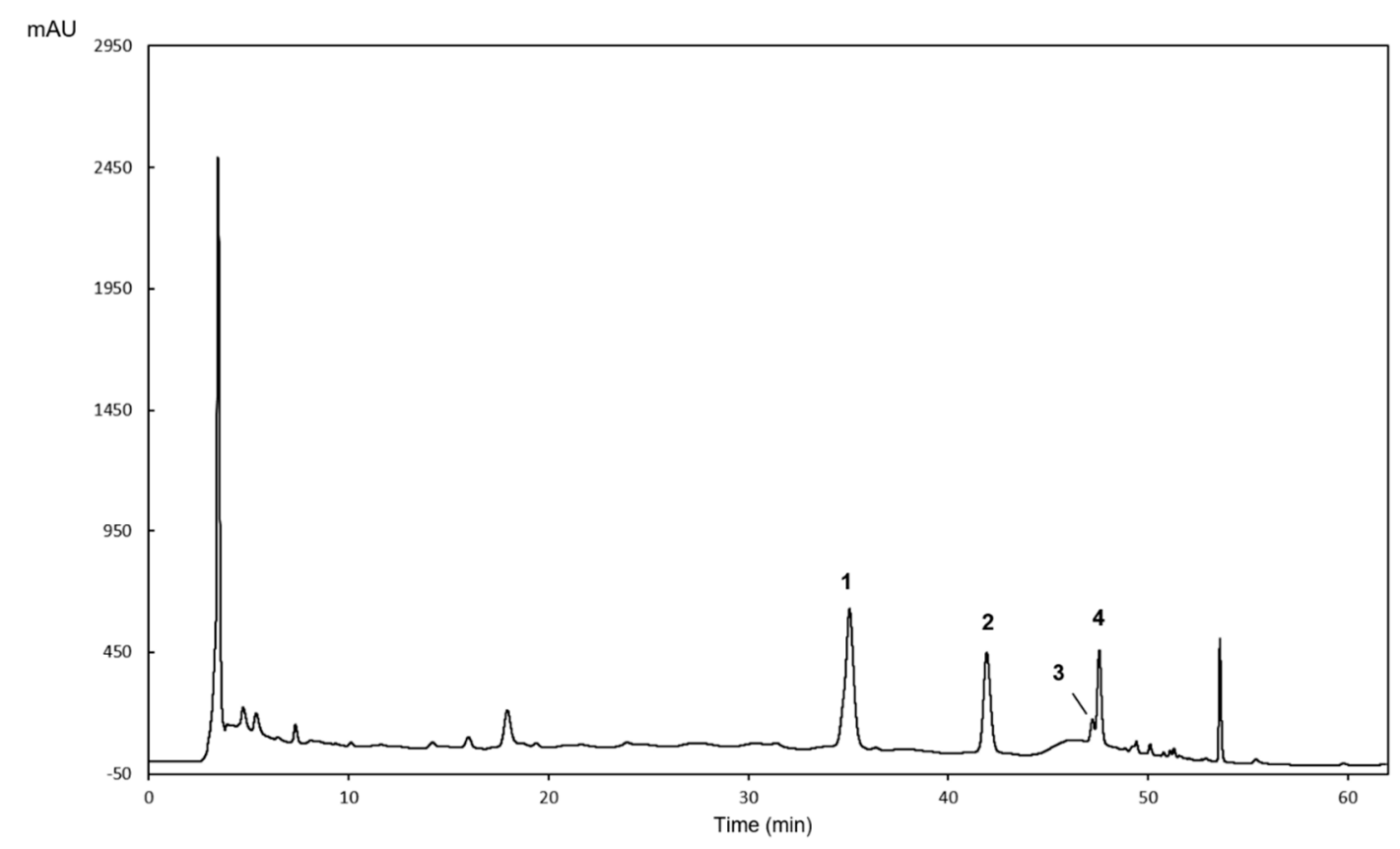

Figure 1. HPLC-UV $(252 \mathrm{~nm})$ phenolic profile of the methanolic extract obtained from H. bhamoense trunk bark. Identity of compounds as in Table 1.

Table 1. Content of ellagic acid and derivatives on the methanol extract of $H$. bhamoense trunk bark.

\begin{tabular}{lcc}
\hline \multicolumn{1}{c}{ Compound } & $\boldsymbol{R}_{\mathbf{t}}$ & $\mathbf{~ m g ~ K g}^{-\mathbf{1}}$ (Dry Extract) \\
\hline 1 Ellagic acid & 34.6 & $2363.30 \pm 53.89$ \\
2 Methyl ellagic acid pentoside & 42.4 & $1590.60 \pm 25.51$ \\
3 Methyl ellagic acid & 47.0 & $551.52 \pm 4.38$ \\
deoxyhexoside & & \\
4 Methyl ellagic acid & 47.5 & $1029.36 \pm 10.45$ \\
& Total & $5534.78 \pm 94.23$ \\
\hline
\end{tabular}

\subsection{H. bhamoense Trunk Bark Extract Significantly Inhibits Hyaluronidase and 5-Lipoxygenase}

Hyaluronan is a straight-chain glycosaminoglycan carbohydrate polymer detected in all vertebrate tissues, its bulk being produced and deposited in the skin [23]. Its degradation is initiated by hyaluronidases, which leads to the formation of midsized and small fragments having several functional implications, namely acting as distress signals with postulated functions in wound scar formation and accompanying inflammatory responses [12].

In most of the mainstay in vitro assays, hyaluronidase obtained from bovine testes is commonly used, since it is commercially available in a reasonably pure form. In contrast with bacterial hyaluronidases, mostly leading to the production of unsaturated disaccharides with limited biological functions, the oligomers resulting from the enzymatic activity of the vertebrates' homologous display a wide range of size-specific effects [24]. In fact, fold-recognition studies indicate that the catalytic 
clefts and the active sites are highly conserved between human and bovine hyaluronidases, the latter being structurally representative of all vertebrate hyaluronidases [24].

Our results demonstrate that the methanol extract obtained from H. bhamoense trunk bark significantly interferes with the activity of hyaluronidase from bovine testes, at concentrations ranging from 125 to $1000 \mu \mathrm{g} \mathrm{mL}^{-1}$, with an $\mathrm{IC}_{50}$ value of $396.9 \pm 25.7 \mu \mathrm{g} \mathrm{mL}^{-1}$ being recorded. (Figure $2 \mathrm{~A}$ ). Relevantly, recorded inhibitory effects were stronger than those observed with the well-known inhibitor disodium cromoglycate. As some classes of polyphenols have been described as inhibitors of hyaluronidase, the observed effects might be related to the content in ellagic acid derivatives [25]. In a previous study, Kuppusami and Das [25] noted that non-glycosylated derivatives of ellagic acid were able to cause more than $90 \%$ of inhibition. Due to the high content of ellagic acid (1) in the methanol extract obtained from $H$. bhamoense trunk bark (Table 1), it seems plausible to consider that the effects may at least partially derive from the inhibitory capacity of this compound. At active concentrations (750-1000 $\mathrm{\mu g} \mathrm{mL}^{-1}$ ) (Figure 2A), the trunk bark extract was found to exhibit a high content in 1, above the $\mathrm{IC}_{50}$ value of $1.5 \pm 0.1 \mu \mathrm{g} \mathrm{mL} \mathrm{m}^{-1}$ recorded by Sgariglia et al. [26]. Partial contribution of 4 cannot be excluded as the methylated derivative is also reported to act as an efficient hyaluronidase inhibitor $\left(\mathrm{IC}_{50}=2.3 \pm 0.1 \mu \mathrm{g} \mathrm{mL}^{-1}\right)[26]$.

A

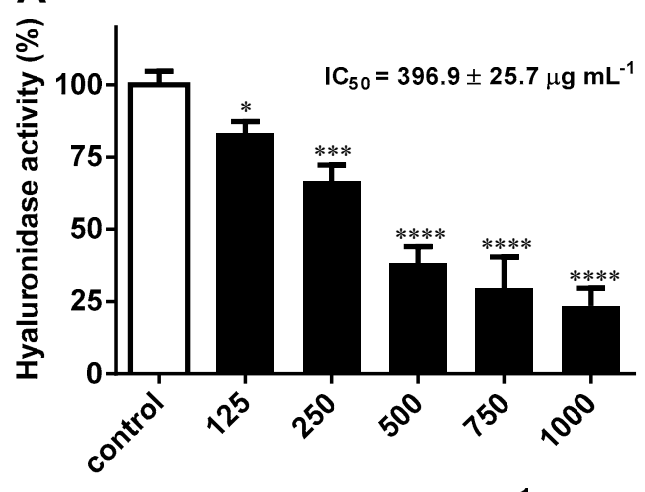

Concentration $\left(\mu \mathrm{gLL}^{-1}\right)$
B

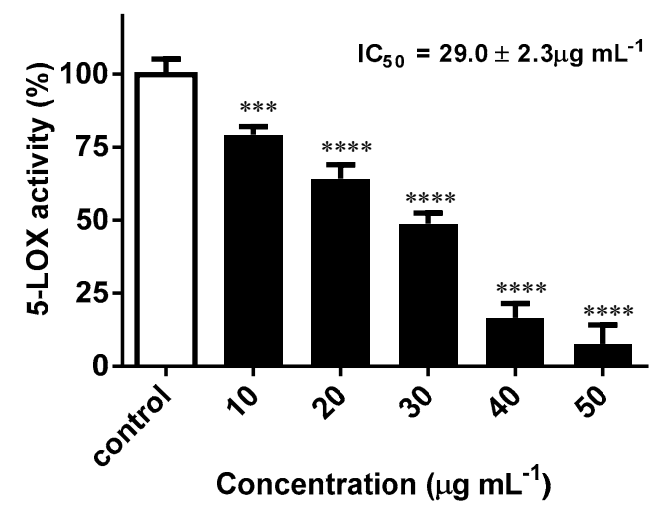

Figure 2. Inhibitory effects towards hyaluronidase (A) and 5-lipoxygenase (B) activity upon exposure to H. bhamoense trunk bark methanol extract. The results correspond to the mean \pm SEM of three independent experiments performed in triplicate (statistical significance: ${ }^{*} p<0.05,{ }^{* * *} p<0.001$ and **** $p<0.0001)$.

While hyaluronidases are particularly relevant as enzymatic targets on cutaneous repair, 5-LOX has been increasingly found to play also a critical role. The enzyme catalyzes the initial steps in the conversion of arachidonic acid to leukotrienes [27]. The biosynthesis of lipidic mediators is also related to an increased production of ROS [27] and underlies the inflammatory response in wound healing, with the disruption of 5-LOX being found to improve cutaneous healing [10,28]. Furthermore, classical symptoms of inflammation such as pain, reddening and edema of the surrounding tissue during cutaneous wound healing are caused by the release of eicosanoids [29].

While proving to be less effective than the reference inhibitor quercetin $\left(\mathrm{IC}_{50}=8.3 \mu \mathrm{g} \mathrm{mL}{ }^{-1}\right)$, the trunk bark extract led to a significant decrease in 5-LOX activity with concentration dependence (Figure 2B). As seen on Figure 2B, the trunk bark extract proved to be active at concentrations as low as $10 \mu \mathrm{g} \mathrm{mL}^{-1}$, displaying an $\mathrm{IC}_{50}$ value of $29.0 \pm 2.3 \mu \mathrm{g} \mathrm{mL}^{-1}$. Ellagic acid derivatives, particularly ellagic acid (1), have been ascribed as anti-inflammatory agents interfering with several inflammatory mediators [30], and while there are no reports on the specific inhibitory effects towards 5-LOX, Kawakami et al. [31] recorded a concentration-dependent inhibition against the 12-lipoxygenase isoform. 


\subsection{Effects on NO Levels and Inflammatory Cytokines in LPS-Stimulated RAW 264.7 Macrophages}

In addition to their phagocytic activity, macrophages play a pivotal role in wound healing, namely in the production and release of mediators involved in the transition from the exudative to the proliferative phase, being the most abundant hematopoietic population in intact skin [13]. NO generally acts as mediator of skin homeostasis and wound repair, influencing collagen deposition and the strength of incisional wounds. However, increased levels lead to an inflammatory response, subsequently activating the synthesis of additional proinflammatory mediators and the proteolytic degradation of extracellular matrix components that dictate the outcome of tissue repair [12,32]. NO release in immune cells, such as macrophages, is activated either through internal stimuli or environmental stressors [33]. For example, NO synthesis is markedly influenced by hyaluronan, its polydisperse fragments mediating inflammatory cell recruitment and promoting the activation of macrophages, namely inducing the expression of inducible nitric oxide synthase (iNOS) and the subsequent production of $\mathrm{NO}$ in the early phase of wound healing [32].

The nitrite $\left(\mathrm{NO}_{2}{ }^{-}\right)$accumulated in the culture medium of LPS-challenged RAW 264.7 macrophages was used as an index for NO synthesis. Impact on cellular viability was first assessed, results showing no noticeable cytotoxicity after $24 \mathrm{~h}$ treatment at concentrations up to $1000 \mu \mathrm{g} \mathrm{mL}^{-1}$ (Figure 3A). Pretreatment with the methanol extract obtained from $H$. bhamoense trunk bark significantly decreased NO levels induced by LPS down to approximately $79 \%$ at the highest concentration tested $(p<0.01)$ (Figure 3B). A biphasic effect was observed, as the extract led to a significant increase in NO levels at $250(p<0.05)$ and $500 \mu \mathrm{g} \mathrm{mL}^{-1}(p<0.01)$ (Figure 3B).

A

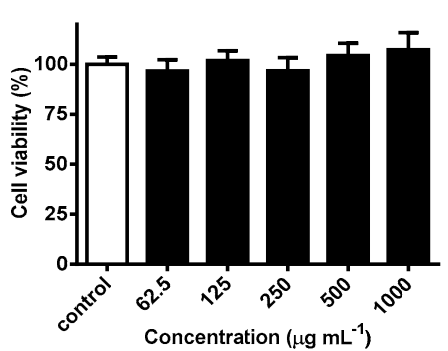

B

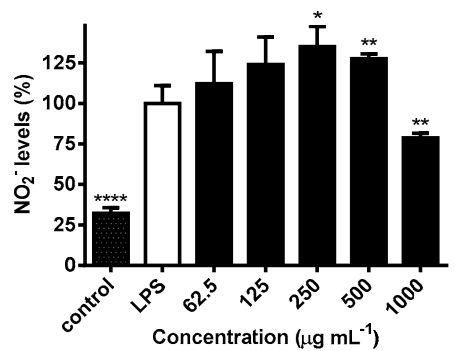

C

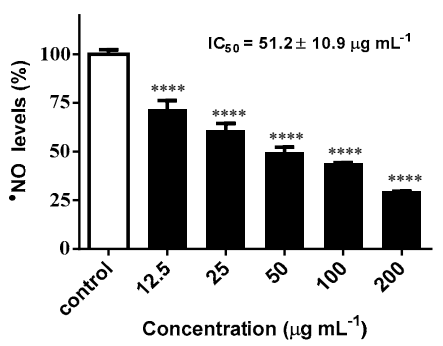

Figure 3. Effects of $H$. bhamoense trunk bark extract on RAW 264.7 cell viability (A), $\mathrm{NO}_{2}{ }^{-}$levels in lipopolysaccharide (LPS)-challenged RAW 264.7 cells (B), and ${ }^{\bullet} \mathrm{NO}$ levels in a cell-free assay (C). Results correspond to the mean \pm SEM of three independent experiments performed in triplicate (statistical significance: ${ }^{*} p<0.05,{ }^{* *} p<0.01$ and $\left.{ }^{* * * *} p<0.0001\right)$.

The evaluation of antiradical activity in a chemical system showed evidence that the reduction of NO levels might be associated with a pronounced scavenging capacity, as significant effects were observed at concentrations as low as $12.5 \mu \mathrm{g} \mathrm{mL}^{-1}(p<0.0001)$ (Figure $3 \mathrm{C}$ ). On the basis of the low $\mathrm{IC}_{50}$ value of $51.2 \pm 10.9 \mu \mathrm{g} \mathrm{mL}^{-1}$ (Figure $3 \mathrm{C}$ ), the strong scavenging capacity upon ${ }^{\bullet} \mathrm{NO}$ might contribute to the observed reduction in $\mathrm{NO}_{2}{ }^{-}$levels recorded in the cell-based assay upon exposure to the extract at the highest concentration tested (Figure 3B).

Activated macrophages also secrete excessive amounts of inflammatory cytokines, such as TNF- $\alpha$ and interleukins, which propagate local inflammation [13]. As such, in addition to NO, production of TNF- $\alpha$ and IL- 6 is also frequently employed as criteria to evaluate anti-inflammatory properties, their secretion in the culture of LPS-induced RAW 264.7 macrophages being measured by ELISA assays. The inhibitory effects of $H$. bhamoense trunk bark extract on the proinflammatory cytokines TNF- $\alpha$ and IL- 6 are expressed as relative values (measured as pg cytokine/ $\mu \mathrm{g}$ of total protein) and are shown in Figure 4. 
A

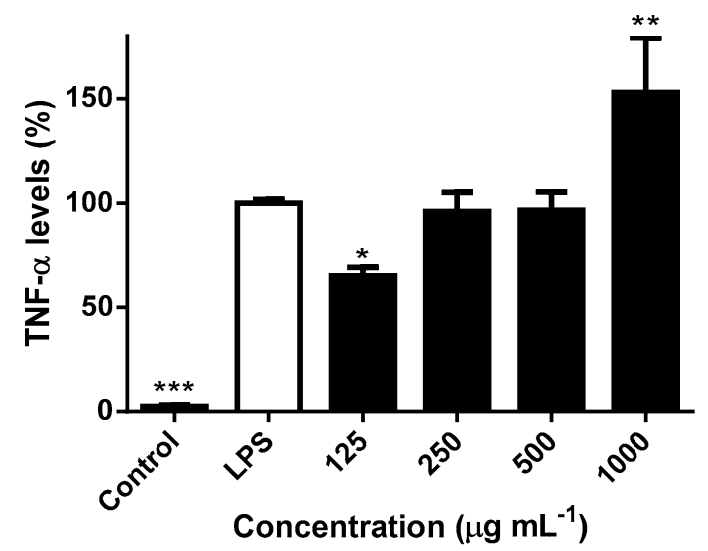

B

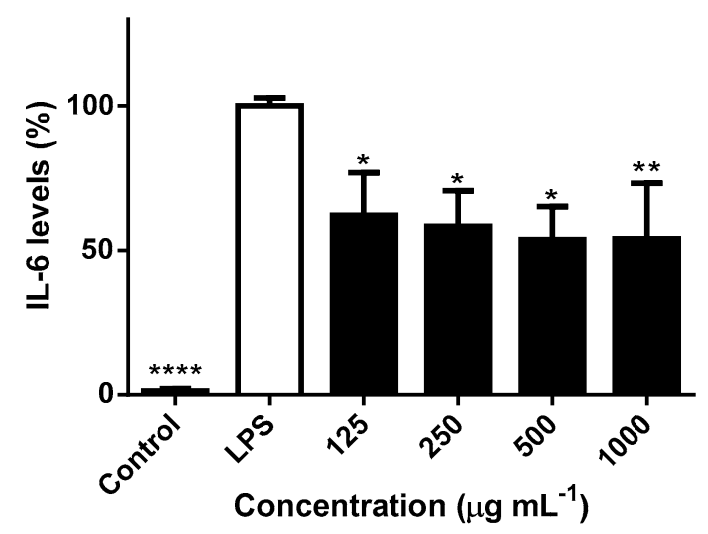

Figure 4. Effects of $H$. bhamoense trunk bark extract on tumor necrosis factor alpha (TNF- $\alpha)(\mathbf{A})$ and interleukin-6 (IL-6) levels (B) in LPS-challenged RAW 264.7 cells. Results correspond to the mean \pm SEM of three independent experiments performed in triplicate (statistical significance: ${ }^{*} p<0.05,{ }^{* *} p<0.01$, $* * * p<0.001$ and $\left.{ }^{* * * *} p<0.0001\right)$.

A biphasic effect on TNF- $\alpha$ was recorded, characterized by a significant decrease of cytokine levels upon exposure to the extract at $125 \mu \mathrm{g} \mathrm{mL}-1(p<0.05)$ in contrast with a significant increase $(p<0.01)$ at the highest concentration tested (Figure 4A). In alignment with our results (Figure 4A), ellagic acid (1) may exert a biphasic effect upon TNF- $\alpha$ in RAW 264.7 cells, as Du et al. [34] reported that it is able to attenuate the cytokine protein levels at concentrations ranging from 1 to $50 \mu \mathrm{M}$, but did not prove to impact TNF- $\alpha$ production at concentrations higher than $63 \mu \mathrm{M}[35,36]$. According to our results, the significant increase on TNF- $\alpha$ levels at $1000 \mu \mathrm{g} \mathrm{mL}^{-1}(p<0.01)$ might contribute to the wound healing properties of $H$. bhamoense trunk bark, as the cytokine plays a pivotal role in the early phase of wound repair. Increased levels of TNF- $\alpha$ empower the activation of macrophages and acquisition of a proinflammatory M1 phenotype, that enables phagocytosis of microbes and scavenging of dead cells and debris, required for proper cutaneous healing [37]. The effects upon TNF- $\alpha$ synergise the recorded impact of $H$. bhamoense trunk bark towards NO, which has cytostatic, chemotactic and cytotoxic activity against various microorganisms involved in cutaneous infections [38]. TNF- $\alpha$ signalling transiently activates canonical nuclear factor kappa B (NF- $\mathrm{BB}$ ) target genes, mediating the stimulation of IL-6 production and other cytokines [13,39]. Cutaneous healing is highly regulated by gradients of different cytokines and inflammatory mediators through an intricate and complex network [39]. For example, iNOS is known to be induced by TNF- $\alpha$, but generated NO may, in turn, modulate TNF- $\alpha$ release. Previous studies demonstrate that NO interferes with cytokine cascades, namely by inducing TNF- $\alpha$ mRNA in RAW 264.7 macrophages [40], neutralization of radical species being also associated with the reduction of TNF- $\alpha$ levels [38].

Compared with the exposure to LPS, the extract obtained from H. bhamoense trunk bark proved to significantly reduce IL-6 down to levels ranging from $53.7 \%$ to $62.1 \%$ at the whole range of concentrations (125-1000 $\mu \mathrm{g} \mathrm{mL}^{-1}$ ) (Figure 4B). While TNF- $\alpha$ induces inflammatory effects by acting directly on multiple target tissues and by inducing other cytokines, such as IL-6 [13], IL-6 also appears to modulate its production. In agreement with our results (Figures 3B and 4), Marcinkiewicz et al. [41] demonstrated that inhibition of IL-6 leads to an enhancement of NO and TNF- $\alpha$ in mouse macrophages. Furthermore, Deakin et al. [42] reported that IL-6 production was attenuated in NO-stimulated mouse macrophages, further suggesting that inhibition of IL- 6 by NO may potentiate TNF- $\alpha$ release. The extract obtained from the trunk bark of $H$. bhamoense exerts significant inhibition upon IL-6 levels in LPS-challenged RAW 264.7 macrophages (Figure 4B), suggesting that it may impact the initiation of the cutaneous healing response, as the expression of the effector mediator IL- 6 is known to be increased after wounding and persists in older wounds [43]. Ellagic acid derivatives might account to the observed effects, as ellagic acid (1) has been reported to significantly decrease IL-6 at the 
mRNA and protein levels in RAW 264.7 cells stimulated with LPS, at concentrations as low as those found in $H$. bhamoense trunk bark extract at active concentrations (500 and $1000 \mu \mathrm{g} \mathrm{mL}{ }^{-1}$ ) (Table 1 and Figure 4B) [34,44].

\subsection{Effects in the Viability of Human Keratinocyte HaCaT Cells}

Keratinocytes act as the first barrier of protection against external aggressors, being the most common cell type of the human epidermis $[45,46]$. Besides acting as building blocks of the skin, keratinocytes also play an active role in inflammatory processes, their cellular integrity being essential to attain a proper cutaneous healing [45]. As such, human epidermal keratinocytes are one of the most appropriate cell lines to evaluate skin biocompatibility and cytotoxicity, monolayer cultures of HaCaT cells being one of the most conventional in vitro models to address topical safety [46].

To determine whether H. bhamoense trunk bark extract might exhibit cutaneous toxicity, spontaneously immortalized human keratinocyte HaCaT cells were used as a model. Viability assay testing was attained at concentrations that scored positively in the enzymatic (Figure 2) and cell-based assays (Figures 3 and 4), Figure 5 depicting the extract's significant cytotoxicity upon $24 \mathrm{~h}$ of exposure solely at $1000 \mu \mathrm{g} \mathrm{mL}^{-1}(p<0.0001)$.

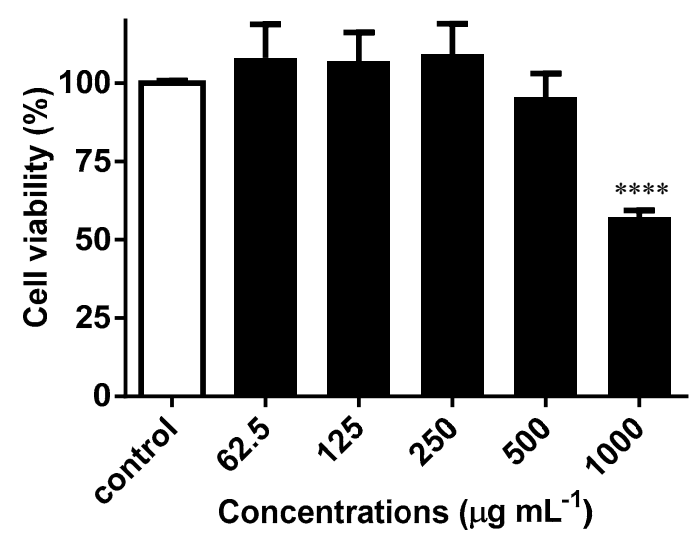

Figure 5. Effects of $H$. bhamoense trunk bark extract on HaCaT cell viability. Results correspond to the mean \pm SEM of three independent experiments performed in triplicate (statistical significance: $* * * * 0<0.0001)$.

\section{Materials and Methods}

\subsection{General Chemicals and Materials}

Methanol p.a. and methanol LiChrosolv ${ }^{\circledR}$ were from Merck KGaA (Darmstadt, Germany). Formic acid was purchased from VWR (Fontenay-sous-Bois, France).

Purified water was treated in a Milli-Q water purification system (Millipore, Bedford, MA, USA). Spectrophotometric determinations were performed in a Multiskan ${ }^{\mathrm{TM}} \mathrm{GO}$ microplate spectrophotometer (Thermo Fisher Scientific Oy, Vantaa, Finland).

\subsection{Collection of Plant Material and Preparation of Crude Extract}

Plant material of H. bhamoense was collected from Wang Man Sub-district, Wat Sing district, Chainat province, Thailand, in March 2015. The plant was identified and authenticated by Dr. Srunya Vajrodaya, Professor of Botany, Faculty of Science, Kasetsart University, Thailand. A voucher specimen of the plant (PCERU_HB1) was deposited at the Phyto-Chemodiversity and Ecology Research Unit, Faculty of Science, Kasetsart University. Samples were air-dried and ground to a fine powder (mean particle size $\leq 910 \mu \mathrm{m}$ ), $2.45 \mathrm{~kg}$ (bark) of powdered material being macerated in $5 \mathrm{~L}$ of methanol for seven days, at $28^{\circ} \mathrm{C}$. Resulting extract was filtered through Whatman ${ }^{\circledR}$ grade 1 filtration paper (Sigma 
Aldrich, St. Louis, MO, USA), concentrated to dryness under reduced pressure in a Büchi Rotavapor ${ }^{\circledR}$ $\mathrm{R}-210$ (Mumbai, India), and stored at $-20^{\circ} \mathrm{C}$ protected from light, until analysis.

\subsection{HPLC-DAD Qualitative and Quantitative Analysis}

Qualitative and quantitative chromatographic analyses were performed on an analytical HPLC unit (Gilson Medical Electronics, Villiers le Bel, France) coupled with an Agilent 1100 series diode array detector (Agilent Technologies, Waldbronn, Germany). Separation was carried out using a $250 \times 4.6 \mathrm{~mm}, 5 \mu \mathrm{m}$, Luna ${ }^{\circledR} 100 \AA$ C18 column (Phenomenex, Torrance, CA, USA), chromatographic conditions as those described in Ferreres et al. [22]. Briefly, a mobile phase consisting of $1 \%$ formic acid in water (A) and methanol (B) was delivered at a flow rate of $0.8 \mathrm{~mL} \mathrm{~min}^{-1}$, starting with $25 \%$ $\mathrm{B}$ and using a gradient to obtain $35 \% \mathrm{~B}$ at $25 \mathrm{~min}, 40 \% \mathrm{~B}$ at $40 \mathrm{~min}, 80 \% \mathrm{~B}$ at $50 \mathrm{~min}$ and $80 \% \mathrm{~B}$ at $55 \mathrm{~min}$. The injection volume was $20 \mu \mathrm{L}$ and the elution was performed at $25^{\circ} \mathrm{C}$. Data processing was performed on Clarity software system 5.04.158 (DataApex Ltd., Prague, Czech Republic). Spectral data were accumulated in the range of $200-700 \mathrm{~nm}$, chromatograms being recorded at $252 \mathrm{~nm}$. Quantitation of the identified compounds was determined from the peak area, using the equation of linear regression obtained from the calibration curve (concentration vs. optical absorbance at $252 \mathrm{~nm}$ ) (Table 2) built with five concentrations (in triplicate) of ellagic acid (Extrasynthèse S.A., Genay, France).

Table 2. Results of linear regression equation analysis, $\mathrm{LOD}^{\mathrm{a}}$ and $\mathrm{LOQ}^{\mathrm{b}}$ for ellagic acid.

\begin{tabular}{ccccccc}
\hline \multicolumn{7}{c}{ Regression Equation } \\
\hline Slope $(\sigma)$ & Intercept $(b)$ & $\boldsymbol{R}^{\mathbf{2}}(n=3)$ & Linearity Range $\left(\mu \mathbf{g ~ m L}^{-1}\right)$ & $\begin{array}{c}\text { LOD } \\
\left(\mu \mathrm{gLL}^{-1}\right)\end{array}$ & $\begin{array}{c}\text { LOQ } \\
\left(\mu \mathrm{gL} \mathrm{mL}^{-1}\right)\end{array}$ \\
\hline Ellagic acid & 164.35 & -3443 & 0.9997 & $26.88-430$ & 3.55 & 10.74 \\
\hline \multicolumn{7}{c}{${ }^{\mathrm{a}}$ Limit of detection; ${ }^{\mathrm{b}}$ Limit of quantification. }
\end{tabular}

\subsection{Enzymatic Assays}

\subsubsection{Inhibition of Hyaluronidase Activity}

Hyaluronidase activity evaluation was carried out spectrophotometrically based on the Morgan-Elson reaction with some modifications [47]. Briefly, $50 \mu \mathrm{L}$ of plant extract, $50 \mu \mathrm{L}$ of a stock solution of hyaluronan (HA; $\left.5 \mathrm{mg} \mathrm{mL}^{-1}\right)$ and $100 \mu \mathrm{L}$ of buffer $(0.2 \mathrm{M} \mathrm{HCOONa}, 0.1 \mathrm{M} \mathrm{NaCl}$ and $0.2 \mathrm{mg} \mathrm{mL}^{-1}$ bovine serum albumin, $\mathrm{pH}=3.68$ ) were added to $200 \mu \mathrm{L}$ of water, reaction being started with the addition of $50 \mu \mathrm{L}$ of hyaluronidase from bovine testes $\left(600 \mathrm{U} \mathrm{mL}^{-1}\right)$ (Type I-S; EC 3.2.1.35; Sigma-Aldrich, St. Louis, MO, USA) prepared in $\mathrm{NaCl} 0.9 \%$. The reaction was terminated by adding $25 \mu \mathrm{L}$ of Borax $(0.8 \mathrm{M})$, and subsequent heating for $3 \mathrm{~min}$ at $95^{\circ} \mathrm{C}$. The test tubes were cooled and $750 \mu \mathrm{L}$ of low acidic solution of $p$-dimethylaminobenzaldehyde (DMAB) was added. The tubes were incubated at $37^{\circ} \mathrm{C}$ for $20 \mathrm{~min}$ and the absorbance was measured at $560 \mathrm{~nm}$. Three independent assays were performed in triplicate, results being compared to the reference hyaluronidase inhibitor sodium cromoglycate.

\subsubsection{Inhibition of 5-Lipoxygenase Activity}

The potential interference with the enzymatic activity of 5-LOX was determined by the linoleic acid oxidation, according to a previously described procedure [48]. Inhibitory reactions were performed at a final volume of $240 \mu \mathrm{L}$, containing $200 \mu \mathrm{L}$ of phosphate buffer $(\mathrm{pH}=9), 20 \mu \mathrm{L}$ of soybean 5 -LOX (EC 1.13.11.12; Sigma-Aldrich, St. Louis, MO, USA) and $20 \mu \mathrm{L}$ of extract. Preincubation at $25^{\circ} \mathrm{C}$ was followed by the addition of linoleic acid $(20 \mu \mathrm{L}, 4.18 \mathrm{mM})$, formation of its oxidation product being followed for $3 \mathrm{~min}$. The absorbance was measured spectrophotometrically at $234 \mathrm{~nm}$, and $\mathrm{IC}_{50}$ values were determined against the known 5-LOX inhibitor quercetin. Each measurement was repeated three times, in triplicate. 


\subsection{Nitric Oxide Radical Scavening Activity}

Nitric oxide radical scavenging activity was based on the Griess reaction as in Ferreres et al. [49]. A total of $100 \mu \mathrm{L}$ sodium nitroprusside $\left(10 \mathrm{mmol} \mathrm{L}^{-1}\right)$ in phosphate buffer saline (PBS) was mixed with $100 \mu \mathrm{L}$ of extract, the mixture being further incubated at $25{ }^{\circ} \mathrm{C}$ for 60 min under light. After incubation, $100 \mu \mathrm{L}$ of Griess reagent (1\% sulfanilamide, $2 \% \mathrm{H}_{3} \mathrm{PO}_{4}$ and $0.1 \%$ naphthylethylene diamine hydrochloride) were added, absorbance being measured at $546 \mathrm{~nm}$. Three experiments were performed in triplicate.

\subsection{Interference with LPS-Induced NO Production by RAW 264.7 Cells}

\subsubsection{Cell Viability}

The effects on cell viability were assessed through the MTT reduction assay [49]. Briefly, RAW 264.7 murine macrophages (ATTC, LGC Standards S.L.U., Barcelona, Spain) were plated in 96-well culture plates at a density of $2.5 \times 10^{4}$ cells well ${ }^{-1}$ and incubated for $24 \mathrm{~h}$ in a water-jacket $\mathrm{CO}_{2}$ incubator $(5 \%$ $\mathrm{CO}_{2}, 37^{\circ} \mathrm{C}$; Toreuse model 2428 ; St. Louis, MO, USA) to reach ca. $80 \%$ confluency. The medium was then replaced with $100 \mu \mathrm{L}$ of plant extract in DMEM and cultured for $24 \mathrm{~h}$. Mitochondrial performance was evaluated through the addition of MTT solution $\left(0.5 \mathrm{mg} \mathrm{mL}^{-1}\right)$, the plate being incubated for $90 \mathrm{~min}$ at $37^{\circ} \mathrm{C}$. Resulting formazan crystals were dissolved in a mixture of DMSO:isopropanol and absorbance was measured at $560 \mathrm{~nm}$.

\subsubsection{Nitrite Assay}

Nitrite levels were used as an indicator of the amount of NO, being determined by Griess reagent (1\% sulphanilamide and $0.1 \% \mathrm{~N}$-(naphth-1-yl)ethylenediamine dihydrochloride in $2 \% \mathrm{H}_{3} \mathrm{PO}_{4}$ ), as described in Ferreres et al. [49]. Briefly, RAW 264.7 murine macrophages were plated into 96-well plates at a density of $3.5 \times 10^{5}$ cells $\mathrm{mL}^{-1}$ and incubated until confluent. Cells were then pretreated with different concentrations of the plant extracts for $2 \mathrm{~h}$ and stimulated with LPS $\left(1 \mu \mathrm{g} \mathrm{mL}{ }^{-1}\right)$. Plates were further incubated for $22 \mathrm{~h}$ at $37^{\circ} \mathrm{C}$, in a humidified atmosphere of $5 \% \mathrm{CO}_{2}$, absorbance being read at $540 \mathrm{~nm}$.

\subsection{Interference with LPS-Induced TNF- $\alpha$ and IL-6 Production by RAW 264.7 Cells}

\subsubsection{Enzyme-Linked Immunosorbent Assay (ELISA)}

The amount of TNF- $\alpha$ and IL- 6 released by the LPS-challenged RAW 264.7 murine macrophages was measured by using mouse IL-6 ELISA MAX ${ }^{\mathrm{TM}}$ Deluxe and mouse TNF- $\alpha$ ELISA MAX ${ }^{\mathrm{TM}}$ Deluxe kits (BioLegend Inc., San Diego, CA, USA) [48]. RAW 264.7 cells were cultured at a concentration of $3.5 \times 10^{5}$ cells mL $\mathrm{mL}^{-1}$ and incubated for $24 \mathrm{~h}\left(37^{\circ} \mathrm{C}, 5 \% \mathrm{CO}_{2}\right)$. After discarding the medium, H. bhamoense trunk bark extract was added to each well at concentrations ranging from 125 to $1000 \mu \mathrm{gL}^{-1}$ and incubated for $24 \mathrm{~h}$. Following post-incubation, the cells were treated with LPS $\left(1 \mu \mathrm{g} \mathrm{mL} \mathrm{L}^{-1}\right)$ for $24 \mathrm{~h}$, culture supernatant being collected and stored at $-80^{\circ} \mathrm{C}$ until analyzed.

\subsubsection{Total Protein Quantification}

Protein concentration was calculated by regression analysis using a standard curve obtained with a solution of bovine serum albumin (BSA), as in Macedo et al. [48]. Colorimetric measurements were attained at $595 \mathrm{~nm}$.

\subsection{Interference with $\mathrm{HaCaT}$ Cells' Viability}

The effects on the mitochondrial viability of HaCaT cells were assessed through the MTT reduction assay [50]. Briefly, after treatment with $0.25 \%$ trypsin solution (GIBCO, Invitrogen, Grand Island, NY, US), human epidermal HaCaT keratinocytes $\left(\mathrm{ATCC}^{\circledR}\right.$ ) were seeded into 96-well plates at a density of $1.5 \times 10^{4}$ cells well ${ }^{-1}$ in a water-jacket $\mathrm{CO}_{2}$ incubator $\left(5 \% \mathrm{CO}_{2}, 37^{\circ} \mathrm{C}\right.$; Toreuse model 2428 ; St. Louis, 
MO, USA) and grown until reaching ca. $80 \%$ confluency after $24 \mathrm{~h}$. Then, cells were incubated with $100 \mu \mathrm{L}$ of plant extract in DMEM GlutaMAX ${ }^{\mathrm{TM}}$ and cultured for $24 \mathrm{~h}$. MTT solution $\left(0.5 \mathrm{mg} \mathrm{mL}^{-1}\right)$ was added into each well and incubated for $90 \mathrm{~min}$ at $37^{\circ} \mathrm{C}$. Subsequently, the MTT solution in each well was removed, with DMSO:isopropanol (3:1) being added. The absorbance was measured at $560 \mathrm{~nm}$. Results correspond to the mean \pm SEM of three independent experiments performed in triplicate.

\subsection{Statistical Analysis}

Statistical analysis was performed by using GraphPad Prism 6.01 software (San Diego, CA, USA). The results of the cell-free experiments were expressed as average $\mathrm{IC}_{50}$ values. The results of the experiments were expressed as mean \pm SEM, significance between different groups being determined by one-way analysis of variance (ANOVA), followed by Dunnett's multiple comparison test. $p$ values below 0.05 were considered statistically significant.

\section{Conclusions}

In light of the aforementioned information, H. bhamoense trunk bark exhibits significant inhibitory properties upon a series of inflammatory mediators involved in wound healing, calling for additional in vitro assays covering cutaneous regeneration as well as the translation to in vivo models of disease. The extract was able to regulate the inhibitory effects of hyaluronidase and 5-LOX in a concentration-dependent manner and may represent one of the cutaneous wound healing mechanisms of $H$. bhamoense. Data from cell-based assays revealed that the methanol extract obtained from the trunk bark of the plant has a biphasic impact on the production of NO and TNF- $\alpha$ in RAW 264.7 macrophages, which seems to be related with its use in folk medicine, namely on the elimination of wound debris and on the inhibition of microorganisms underlying cutaneous infections. However, it is worth emphasizing the effects on the release of the proinflammatory cytokine IL-6, potentially hampering inflammatory processes that delay or impair a normal wound healing.

While additional active components remain to be identified, experimental data suggests that ellagic acid and derivatives might contribute to the recorded anti-inflammatory effects.

Results of this study also have provided scientific basis for the traditional use of $H$. bhamoense, as the trunk bark is expected to accelerate the skin wound healing, as suggested by the enhanced resolution of inflammation in experimental models.

Author Contributions: Conceptualization, S.D. and N.G.M.G.; data curation, P.B.A., P.V., S.D. and N.G.M.G.; investigation, R.S., A.P.O. and N.G.M.G.; resources, P.B.A. and S.D.; supervision, S.D. and N.G.M.G.; writing-original draft, R.S.; writing-review and editing, P.B.A., P.V., S.D. and N.G.M.G. All authors have read and agreed to the published version of the manuscript.

Funding: This work was supported by the "Graduate Program Scholarship from the Graduate School of Kasetsart University", "Bilateral Research Cooperation (BRC), Department of Botany, Faculty of Science, Kasetsart University", "The Higher Education Research Promotion and National Research University Project of Thailand, Office of the Higher Education Commission" and "Strengthening and Developing New Researcher Plan, in conformance with the Research and Innovation of Graduate study Strategy of the National Research Council of Thailand (NRCT) as of the fiscal year 2019". This work was supported by UIDB/50006/2020 with funding from FCT/MCTES through national funds and by Programa de Cooperación Interreg V-A España-Portugal (POCTEP) 2014-2020 (project 0377_IBERPHENOL_6_E). To all financing sources the authors are greatly indebted.

Acknowledgments: This work was supported by national funds through FCT-Fundação para Ciência e a Tecnologia, I.P., under the project CEECIND/03037/2017. Andreia P. Oliveira thanks to REQUIMTE for the research contract (DL57/2016/CP1346/CT0015).

Conflicts of Interest: The authors declare no conflict of interest. 


\section{Abbreviations}

\begin{tabular}{|c|c|}
\hline 5-LOX & 5-Lipoxygenase \\
\hline $\operatorname{ATCC}^{\circledR}$ & American Type Culture Collection \\
\hline ELISA & Enzyme-Linked Immunosorbent Assay \\
\hline iNOS & Inducible nitric oxide synthase \\
\hline IL-6 & Interleukin-6 \\
\hline LPS & Lipopolysaccharide \\
\hline $\mathrm{NF}-\kappa \mathrm{B}$ & Nuclear factor kappa B \\
\hline $\mathrm{NO}$ & Nitric oxide \\
\hline TNF- $\alpha$ & Tumor necrosis factor $\alpha$ \\
\hline
\end{tabular}

\section{References}

1. Mahapatra, A.K.; Pani, S.S.; Sahoo, A.K. Free radical-scavenging activities of Homalium species-An endangered medicinal plant of Eastern Ghats of India. Nat. Prod. Res. 2015, 29, 2112-2116. [CrossRef] [PubMed]

2. Prescott, T.A.K.; Homot, P.; Lundy, F.T.; Fang, R.; Patrick, S.; Cámara-Leret, R.; Kiapranis, R. Tropical ulcer plant treatments used by Papua New Guinea's Apsokok nomads. J. Ethnopharmacol. 2017, 205, 240-245. [CrossRef] [PubMed]

3. Sahoo, A.K.; Dash, U.C.; Kanhar, S.; Mahapatra, A.K. In vitro biological assessment of Homalium zeylanicum and isolation of lucidenic acid A triterpenoid. Toxicol. Rep. 2017, 4, 274-281. [CrossRef] [PubMed]

4. Okokon, J.E.; Okokon, P.J.; Dar Farooq, A.; Choudhary, M.I. Anti-inflammatory and antinociceptive activities of Homalium letestui. Pharm. Biol. 2013, 51, 1459-1466. [CrossRef] [PubMed]

5. Sandhya, S.; Sai Kumar, P.; Vinod, K.R.; Banji, D.; Kumar, K. Plants as potent anti-diabetic and wound healing agents-A review. Hygeia J. D. Med. 2011, 3, 11-19.

6. Prescott, T.A.K.; Briggs, M.; Kiapranis, R.; Simmonds, M.S.J. Medicinal plants of Papua New Guinea's Miu speaking population and a focus on their use of plant-slaked lime mixtures. J. Ethnopharmacol. 2015, 174, 217-223. [CrossRef]

7. Sleumer, H. The Flacourtiaceae of Thailand. Blumea 1985, 30, 217-250.

8. Wiart, C. Medicinal Plants Classified in the Family Flacourtiaceae. In Medicinal Plants of Asia and the Pacific; Wiart, C., Ed.; CRC Taylor \& Francis Group: Boca Raton, FL, USA, 2006; pp. 97-98.

9. Maytin, E.V. Hyaluronan: More than just a wrinkle filler. Glycobiology 2016, 26, 553-559. [CrossRef]

10. Guimarães, F.R.; Sales-Campos, H.; Nardini, V.; da Costa, T.A.; Fonseca, M.T.C.; Júnior, V.R.; Sorgi, C.A.; da Silva, J.S.; Chica, J.E.L.; Faccioli, L.H.; et al. The inhibition of 5-lipoxygenase (5-LO) products leukotriene $\mathrm{B} 4\left(\mathrm{LTB}_{4}\right)$ and cysteinyl leukotrienes (cysLTs) modulated the inflammatory response and improves cutaneous wound healing. Clin. Immunol. 2018, 190, 74-83. [CrossRef]

11. Toole, B.P. Hyaluronan: From extracellular glue to pericellular cue. Nat. Rev. Cancer 2004, 4, 528-539. [CrossRef]

12. Liang, J.; Jiang, D.; Noble, P.W. Hyaluronan as a therapeutic target in human diseases. Adv. Drug Deliv. Rev. 2016, 97, 186-203. [CrossRef] [PubMed]

13. Larouche, J.; Sheoran, S.; Maruyama, K.; Martino, M.M. Immune regulation of skin wound healing: Mechanisms and novel therapeutic targets. Adv. Wound Care (New Rochelle) 2018, 7, 209-231. [CrossRef] [PubMed]

14. Pereira, R.F.; Bártolo, P.J. Traditional therapies for skin wound healing. Adv. Wound Care (New Rochelle) 2016, 5, 208-229. [CrossRef] [PubMed]

15. Manca, M.L.; Zaru, M.; Bacchetta, G.; Biggio, T.; Cappai, N.; Cabras, A.; Falchi, A.M.; Manconi, M.; Fadda, A.M. A new technological approach to improve the efficacy of a traditional herbal medicinal product in wound healing. Ind. Crop. Prod. 2015, 63, 71-78. [CrossRef]

16. Castangia, I.; Caddeo, C.; Manca, M.L.; Casu, L.; Latorre, A.C.; Díez-Sales, O.; Ruiz-Saurí, A.; Bacchetta, G.; Fadda, A.M.; Manconi, M. Delivery of liquorice extract by liposomes and hyalurosomes to protect the skin against oxidative stress injuries. Carbohydr. Polym. 2015, 134, 657-663. [CrossRef] 
17. Manca, M.L.; Castangia, I.; Zaru, M.; Nácher, A.; Valenti, D.; Fernàndez-Busquets, X.; Fadda, A.M.; Manconi, M. Development of curcumin loaded sodium hyaluronate immobilized vesicles (hyalurosomes) and their potential on skin inflammation and wound restoring. Biomaterials 2015, 71, 100-109. [CrossRef]

18. Ekabo, O.A.; Farnsworth, N.R.; Santisuk, T.; Reutrakul, V. Phenolic, iridoid and ionyl glycosides from Homalium ceylanicum. Phytochemistry 1993, 32, 747-754. [CrossRef]

19. Liu, L.; Guo, Z.; Chai, X.; Zhao, M.; Lu, Y.; Tu, P. Phenolic glycosides from the stems of Homalium ceylanicum (Gardner) Bentham (Flacourtiaceae/Salicaceae sensu lato). Biochem. Syst. Ecol. 2013, 46, 55-58. [CrossRef]

20. Zhang, Z.Q.; Zheng, C.J.; Bai, M.; Li, X.B.; Song, X.P.; Han, C.R. Cytotoxic constituents of the twigs of Homalium stenophyllum. Chem. Nat. Compd. 2017, 53, 362-364. [CrossRef]

21. Wu, S.Y.; Fu, Y.H.; Zhou, Q.; Bai, M.; Chen, G.Y.; Han, C.R.; Song, X.P. A new dihydrochalcone glycoside from the stems of Homalium stenophyllum. Nat. Prod. Res. 2018, 32, 953-958. [CrossRef]

22. Ferreres, F.; Grosso, C.; Gil-Izquierdo, A.; Valentão, P.; Andrade, P.B. Ellagic acid and derivatives from Cochlospermum angolensis Welw. extracts: HPLC-DAD-ESI/MS ${ }^{\mathrm{n}}$ profiling, quantification and in vitro anti-depressant, anti-cholinesterase and anti-oxidant activities. Phytochem. Anal. 2013, 24, 534-540. [CrossRef] [PubMed]

23. Stern, R.; Maibach, H.I. Hyaluronan in skin: Aspects of aging and its pharmacologic modulation. Clin. Dermatol. 2008, 26, 106-122. [CrossRef] [PubMed]

24. Stern, R.; Jedrzejas, M.J. The hyaluronidases: Their genomics, structures, and mechanisms of action. Chem. Rev. 2008, 106, 818-839. [CrossRef] [PubMed]

25. Kuppusami, U.R.; Das, N.P. Inhibitory effects of flavonoids on several venom hyaluronidases. Experientia 1991, 47, 1196-1200. [CrossRef]

26. Sgariglia, M.A.; Soberón, J.R.; Cabanes, A.P.; Sampietro, D.A.; Vattuone, M.A. Anti-inflammatory properties of phenolic lactones isolated from Caesalpinia paraguariensis stem bark. J. Ethnopharmacol. 2013, 147, 63-73. [CrossRef]

27. Cho, K.J.; Seo, J.M.; Kim, J.H. Bioactive lipoxygenase metabolites stimulation of NADPH oxidases and reactive oxygens species. Mol. Cells 2011, 32, 1-5. [CrossRef]

28. Brogliato, A.R.; Moor, A.N.; Kesl, S.L.; Guilherme, R.F.; Georgii, J.L.; Peters-Golden, M.; Canetti, C.; Gould, L.J.; Benjamim, C.F. Critical role of 5-lipoxygenase and heme oxygenase-1 in wound healing. J. Investig. Dermatol. 2014, 134, 1436-1445. [CrossRef]

29. Kendall, A.C.; Nicolaou, A. Bioactive lipid mediators in skin inflammation and immunity. Prog. Lipid Res. 2013, 52, 141-164. [CrossRef]

30. El-Shitany, N.A.; El-Bastawissy, E.A.; El-Desoky, K. Ellagic acid protects against carrageenan-induced acute inflammation through inhibition of nuclear factor kappa B, inducible cyclooxygenase and proinflammatory cytokines and enhancement of interleukin-10 via an antioxidant mechanism. Int. Immunopharmacol. 2014, 19, 290-299. [CrossRef]

31. Kawakami, Y.; Hosokawa, T.; Morinaka, T.; Irino, S.; Hirano, S.; Kobayashi, H.; Yoshioka, A.; Suzuki-Yamamoto, T.; Yokoro, M.; Kimoto, M.; et al. Antiatherogenic effect of guava leaf extracts inhibiting leucocyte-type 12-lipoxygenase activity. Food Chem. 2012, 131, 1069-1075. [CrossRef]

32. McKee, C.M.; Lowenstein, C.J.; Horton, M.R.; Wu, J.; Bao, C.; Chin, B.Y.; Choi, A.M.; Noble, P.W. Hyaluronan fragments induce nitric-oxide synthase in murine macrophages through a nuclear factor kappaB-dependent mechanism. J. Biol. Chem. 1997, 272, 8013-8018. [CrossRef] [PubMed]

33. Trachootham, D.; Lu, W.; Ogasawara, M.A.; Nilsa, R.D.; Huang, P. Redox regulation of cell survival. Antioxid. Redox Signal. 2008, 10, 1343-1374. [CrossRef] [PubMed]

34. Du, L.; Li, J.; Zhang, X.; Wang, L.; Zhang, W. Pomegranate peel polyphenols inhibits inflammation in LPS-induced RAW 264.7 macrophages via the suppression of MAPKs activation. J. Funct. Foods 2018, 43, 62-69. [CrossRef]

35. Verotta, L.; Panzella, L.; Antenucci, S.; Calvenzani, V.; Tomay, F.; Petroni, K.; Caneva, E.; Napolitano, A. Fermented pomegranate wastes as sustainable source of ellagic acid: Antioxidant properties, anti-inflammatory action, and controlled release under simulated digestion conditions. Food Chem. 2018, 246, 129-136. [CrossRef] [PubMed]

36. Seo, C.S.; Jeong, S.J.; Yoo, S.R.; Lee, N.R.; Shin, H.K. Quantitative analysis and in vitro anti-inflammatory effects of gallic acid, ellagic acid, and quercetin from Radix Sanguisorbae. Pharmacogn. Mag. 2016, 12, 104-108. [CrossRef] 
37. Landen, N.X.; Li, D.; Stahle, M. Transition from inflammation to proliferation: A critical step during wound healing. Cell Mol. Life Sci. 2016, 73, 3861-3885. [CrossRef]

38. Schwentker, A.; Vodovotz, Y.; Weller, R.; Billiar, T.R. Nitric oxide and wound repair: Role of cytokines? Nitric Oxide 2002, 7, 1-10. [CrossRef]

39. Kalliolias, G.D.; Ivashkiv, L.B. TNF biology, pathogenic mechanisms and emerging therapeutic strategies. Nat. Rev. Rheumatol. 2016, 12, 49-62. [CrossRef]

40. Eigler, A.; Moeller, J.; Endres, S. Exogenous and endogenous nitric oxide attenuates tumor necrosis factor synthesis in the murine macrophage cell line RAW264.7. J. Immunol. 1995, 154, 4048-4054.

41. Marcinkiewicz, J.; Grabowska, A.; Chain, B. Nitric oxide up-regulates the release of inflammatory mediators by mouse macrophages. Eur. J. Immunol. 1995, 25, 947-951. [CrossRef]

42. Deakin, A.M.; Payne, A.N.; Whittle, B.J.R.; Moncada, S. The modulation of IL-6 and TNF- $\alpha$ release by nitric oxide following stimulation of J774 cells with LPS and IFN- $\gamma$. Cytokine 1995, 7, 408-416. [CrossRef] [PubMed]

43. Grellner, W.; Georg, T.; Wilske, J. Quantitative analysis of proinflammatory cytokines (IL-1 $\beta$, IL-6, TNF- $\alpha$ ) in human skin wounds. Forensic Sci. Int. 2000, 113, 251-264. [CrossRef]

44. Guan, S.; Zheng, Y.; Yu, X.; Han, B.; Lu, J. Ellagic acid protects against LPS-induced acute lung injury through inhibition of nuclear factor kappa B, proinflammatory cytokines and enhancement of interleukin-10. Food Agr. Immunol. 2017, 28, 1347-1361. [CrossRef]

45. Barker, J.; Griffiths, C.; Mitra, R.; Dixit, V.; Nickoloff, B.; Griffiths, C. Keratinocytes as initiators of inflammation. Lancet 1991, 337, 211-214. [CrossRef]

46. Wiegand, C.; Hipler, U.C. Evaluation of biocompatibility and cytotoxicity using keratinocyte and fibroblast cultures. Skin Pharmacol. Physiol. 2009, 22, 74-82. [CrossRef]

47. Pinho, B.R.; Sousa, C.; Valentão, P.; Oliveira, J.M.A.; Andrade, P.B. Modulation of basophils' degranulation and allergy-related enzymes by monomeric and dimeric naphthoquinones. PLoS ONE 2014, 9, e90122. [CrossRef]

48. Macedo, T.; Ribeiro, V.; Oliveira, A.P.; Pereira, D.M.; Fernandes, F.; Gomes, N.G.M.; Araújo, L.; Valentão, P.; Andrade, P.B. Anti-inflammatory properties of Xylopia aethiopica leaves: Interference with pro-inflammatory cytokines in THP-1-derived macrophages and flavonoid profiling. J. Ethnopharmacol. 2020, 248, 112312. [CrossRef]

49. Ferreres, F.; Duangsrisai, S.; Gomes, N.G.M.; Suksungworn, R.; Pereira, D.M.; Gil-Izquierdo, A.; Valentão, P.; Choowongkomon, K.; Andrade, P.B. Anti-inflammatory properties of the stem bark from the herbal drug Vitex peduncularis Wall. ex Schauer and characterization of its polyphenolic profile. Food Chem. Toxicol. 2017, 106, 8-16. [CrossRef]

50. Gomes, N.G.M.; Oliveira, A.P.; Cunha, D.; Pereira, D.M.; Valentão, P.; Pinto, E.; Araújo, L.; Andrade, P.B. Flavonoid composition of Salacia senegalensis (Lam.) DC. leaves, evaluation of antidermatophytic effects, and potential amelioration of the associated inflammatory response. Molecules 2019, 24, 2530. [CrossRef] 